\title{
Using Hurst Exponent to Investigate the Impact of RFID Implementation on Supply Chain Dynamics
}

\author{
Chien-Yuan $\mathrm{Su}^{1} \&$ Jinsheng Roan ${ }^{1}$ \\ ${ }^{1}$ Department of Information Management, National Chung Cheng University, Chia-Yi, Taiwan \\ Correspondence: Chien-Yuan Su, Department of Information Management, National Chung Cheng University, \\ Chia-Yi, Taiwan. E-mail: jienyien@gmail.com
}

$\begin{array}{lc}\text { Received: November 18, } 2012 \quad \text { Accepted: March 21, } 2013 \quad \text { Online Published: April 18, } 2013 \\ \text { doi:10.5539/ijbm.v8n10p52 } & \text { URL: http://dx.doi.org/10.5539/ijbm.v8n10p52 }\end{array}$

\begin{abstract}
In recent years Radio Frequency Identification (RFID) is the epochal information technology applications for the supply chain processes optimization. More and more researchers of e-Supply Chain Management (e-SCM) have devoted to measure accurately the RFID implementation benefit. This research investigates the variability and dynamics of multi-level supply chain and proposes insights into how to manage relevant supply chain factors to exterminate or reduce system instability. In addition, we adopted the beer distribution model to construct the simulation model to describe the multi-level supply chain and utilized the Hurst Exponent to analyze the dynamics behavior of inventory under different factors that include lead time, demand pattern, information sharing, and RFID utilization effectualness. The results revealed that lead time and RFID utilization effectualness influence crucially the inventory dynamics under the stock and supply line discrepancies of determined parameters. These indicated that a significant influence of the RFID utilization effectualness on inventory stability, as well as in providing an effectual RFID utilization investment and implementation mode and strategy to managers.
\end{abstract}

Keywords: radio frequency identification, e-supply chain management, beer distribution model, Hurst exponent

\section{Introduction}

In recent years the globalization and specialization of business mode has apparently been general in more enterprises, managers continuously have dedicated numerous capital and integrated distributed resources to improve their supply chain efficacy. The supply chain system is more complex because it implicates a linked series of multiple entities surrounding value adding activities and goods shipping operations from the process of manufacture and distribution. There are numerous uncertainties such as delivery uncertainty, manufacture uncertainty, and demand uncertainty in the complex system (Simchi-Levi et al., 2000). For the purpose of uncertainty decreasing and operation efficacy improving in this complex supply chain, managers dedicated efforts to seek the optimal supply chain, hence the supply chains management (SCM) has been getting considerable attentions not only from the practice but also from academia (Cooper et al., 1997; Malik et al., 2011; Tracey et al., 2005).

Information technology (IT) has been widely utilized in supply chains business to respond rapidly market dynamics (Gunasekaran \& Ngai, 2004; Raghunathan \& Madey, 1999; Tumaini Mujuni Katunzi, 2011; Yee, 2005). Especially, the Radio Frequency Identification (RFID) technology, that is an automatic identification technology which is composed of tags, reader, middleware, and enterprise application systems (e.g., ERP), is getting considerable attentions in the e-supply chains domain. For ascendancy of RFID, it mainly provide a real-time tracking for considerable objects, promote operation efficiency and accuracy, increase supply chain visibility, and reduce reserves and delivery cost (Li et al., 2006; Prater et al., 2006).

RFID in SCM have paid significant attention in supply chain practice and academia over the last few years, nevertheless, these literatures is limited. These literatures mainly focus on inventory management, manufacturing, object tracking, logistics, etc. (Gaukler et al., 2007). In these academic literatures, they mainly adopt case studies (Demiralp et al., 2012; Tzeng et al., 2008), experiments (Wang et al., 2007), analytical models (Heese, 2007; Szmerekovsky \& Zhang, 2008; Szmerekovsky et al., 2011; Zhou, 2009), and simulations (Basinger, 2006; Fleisch \& Tellkamp, 2005; Lee et al., 2004; Leung et al., 2007; Ustundag, 2009) to investigate the potential benefit and effect of RFID for SCM. To aim at these simulation researches, the primary limitation is that the 
assumption of perfect RFID which can eliminate all inefficiency and inaccuracy problems to obliterate misplacements, shipment errors, and stealing in supply chains. In the real RFID applications in supply chain, read rate and system integration for current RFID technology and applications are not unexceptionable. The read rate of RFID is easily affected by liquid, other electromagnetic wave, and metal around space. Reading performances is disturbed and the efficiency of supply chain operations become worse when RFID readers cannot receive return message from tags under these obstructions. Additionally, integration of enterprise application systems and RFID systems is an essential factor for RFID utilization effectualness.

In this regard, the research intends to investigate the chaotic behaviors and dynamics of multi-level supply chains under various factors (demand pattern, demand-information sharing, lead time, and degree of RFID utilization effectualness) and determined parameters (stock and supply line of regressive expectation) through the famous beer distribution simulation model (Jarmain, 1963). The objective of this paper is that intends to construct the simulation model to observe and analyze the impacts of RFID utilization effectualness on the inventory cost dynamics across all supply chain levels through the Hurst Exponent.

\section{The Simulation Model and Chaos Characterization}

The beer distribution supply chain model is originated by MIT Sloan School of Management (Jarmain, 1963). It is a practicable simplification of the multi-level supply chain, which consists of four multiple entities levels that include that factory, distributor, wholesaler, and retailer, this is expressed in Figure 1. In this model, there are two circulation follows that include orders and products. In the orders follow, retailer must estimate the future customers' demands and place timely order to wholesaler to ensure that retailer's inventory can suffice continuously demand. Wholesaler determines how many units to order from a distributor and the distributor places an order to a factory. The factory determines how many units to manufacture production according to related intelligence and distributor's orders. In addition, the products flow is a process that factory deliver products or goods to retailer. Finally, customers purchase goods in retailer.

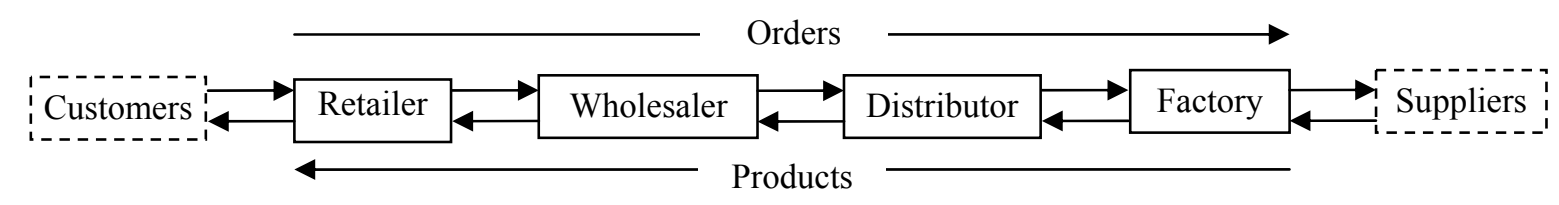

Figure 1. The framework of multi-level supply chain

An important concept in supply chain is the time delays, which is involved in the orders transmission delays, the production transmission delays, and the products shipment delays. These based assumptions of the beer distribution simulation model include that the customers' demand is exogenous and is generated by the step function (this is expressed in Figure 3). The orders transmission delays and the products shipment delays are two kinds of main delay between two successive levels. Besides, the unlimited production capacity and the three time periods of production time. The beer distribution simulation model is regulated by the following rules: (1) Unfilled orders are kept in backlog and shall be filled when the inventory is sufficient; (2) Orders must be filled if inventory is sufficient; (3) Shipments cannot be returned and placed orders cannot be cancelled.

\subsection{System Dynamics of the Supply Chain Model}

Main decision variable for all entities in the simulation model is the number of units to be ordered in each period. Managers must make order decision to keep the minimum inventory holding costs. This decision making is based on information, such as incoming shipments, expected orders, backlog, and the desired and actual inventory levels. In the beer distribution simulation model, the objective is to minimize supply chain costs that are composed of the stockout cost and the inventory holding cost. The stockout cost is double of the inventory holding cost. Finally, there is no demand information sharing in the beer distribution simulation model, hence, each supply chain level manage do not know how the time delays, do not know the state of other supply chain levels and do not know system structure affect the dynamics.

Sterman(1989) proposed the ordering heuristic to anchor and adjust stock management heuristic. The ordering heuristic is introduced to facilitate the model description by the following equations.

The equations of the order quantity at time $O_{t}$ for each entity can be defined as follows: 


$$
\begin{aligned}
O_{t} & =\operatorname{Max}\left(0, I O_{t}\right) \\
& =\operatorname{Max}\left(0, L_{t}+A S_{t}+A S L_{t}\right)
\end{aligned}
$$

The indicated order rate at time $I O_{t}$ is composed by the actual demand at time $L_{t}$, the dissimilarity between desired and actual stock at time $A S_{t}$, and the dissimilarity between desired and actual supply line at time $A S L_{t}$. There is an adaptive expectation in the expectancy of each decision makers, the equations of the expected demand at time $L^{e}$ can be defined as follows:

$$
L_{t}^{e}=\omega L_{t-1}+(1-\omega) L_{t-1}^{e}, 0 \leq \omega \leq 1
$$

In this equation, $\omega$ is the weight factor that determines velocity of updated expectations for expected losses from the stock.

The equations of $A S_{t}$ for each entity can be defined as follows:

$$
A S_{t}=A\left(S^{*}-S_{t}\right), 0 \leq A \leq 1
$$

In this equation, the determined parameter $A$ is the discrepancy elimination between actual stock levels at time $S_{t}$ and desired stock levels $S^{*}$.

The equations of $A S L_{t}$ for each entity can be defined as follows:

$$
A S L_{t}=B\left(S L^{*}-S L_{t}\right), 0 \leq B \leq 1, \text { usually } B \leq A
$$

In this equation, the determined parameter $B$ is the discrepancy elimination between the actual supply line at time $S L_{t}$ and desired supply line $S L^{*}$.

Various ordering heuristic can be presented by these determined parameters setting. This study investigated the dynamics behavior of inventory under each ordering heuristic.

\subsection{Hurst Exponent}

The supply chain system is a representative of the non-linear dynamic, complex, and uncertain system that is originated from numerous uncertainty types, time delay, and feedback processes between entities. Chaos theory is related to chaotic behavior identification in a deterministic nonlinear system through the mathematical methodology and principles (Williams, 1997). These widely quantitative methods of the chaos identification and characterization include the correlation dimension, entropy, Hurst exponent, and Lyapunov exponent (Sprott \& Rowlands, 1995). Particularly, since Hurst exponent is robust with few assumptions about underlying system and has broad applicability for nonlinear time series behavior analysis in finance (Corazza \& Malliaris, 2002; Grech \& Mazur, 2004; Dominique, 2012).

The Hurst exponent is proposed by Hurst (1951) for use in fractal analysis and a measure of long term memory of time series. It relates to the autocorrelations of the time series, and the rate at which these decrease as the lag between pairs of values increases. The Hurst exponent $(H)$ is defined in terms of the asymptotic behaviour of the rescaled range as a function of the time span of a time series (Feder, 1988). Therefore, it can be calculated by rescaled range analysis (R/S analysis). For a time series, $\left\{X_{1}, X_{2}, \ldots, X_{n}\right\}, \mathrm{R} / \mathrm{S}$ analysis method is as follows:

(1) Calculate mean value $m$ of time series.

$$
m=\frac{1}{n} \sum_{i=1}^{n} X_{i}
$$

(2) Calculate mean adjusted series $Y_{t}$

$$
Y_{t}=X_{t}-m, \quad t=1,2, \ldots, n
$$

(3) Calculate cumulative deviate series $Z_{t}$

$$
Z_{t}=\sum_{i=1}^{t} Y_{i}
$$


(4) Calculate range series $R_{t}$

$$
R_{t}=\max \left(Z_{1}, Z_{2}, \ldots, Z_{t}\right)-\min \left(Z_{1}, Z_{2}, \ldots, Z_{t}\right)
$$

(5) Calculate standard deviation series $S_{t}$

$$
S_{t}=\sqrt{\frac{1}{t} \sum_{i=1}^{t}\left(X_{i}-u_{t}\right)^{2}}, \quad u_{t}=\operatorname{mean}\left(X_{1} \sim X_{t}\right)
$$

(6) Calculate rescaled range series $(R / S)_{t}$

$$
(R / S)_{t}=R_{t} / S_{t}
$$

(7) Hurst found that (R/S) scales by power-law as time increases, which indicates $(R / S)_{t}=c \times t^{H_{t}}$, Here $c$ is a constant (c $\approx 0.5$ ) and $H_{t}$ is called the Hurst exponent in $t, \quad H_{t}=\frac{\log \left(R_{t} / S_{t}\right)}{\log (t / 2)}$

(8) Calculate the Hurst exponent for time series $\left\{X_{1}, X_{2}, \ldots ., X_{n}\right\}, H=H_{t=n}$

The values of the Hurst exponent range between 0 and 1, a time series can be classified into three categories. (1) $H=0.5$ indicates a random distribution indistinguishable from noise. (2) $0<H<0.5$ indicates the system shows non-linear dynamics and it is an anti-persistent series(more chaotic). (3) $0.5<H<1.0$ indicates the system shows non-linear dynamics and it is a persistent series (less chaotic).

These advantages of Hurst exponent include that the based assumption is simple and its validity is more stable and robust for numerous types of time series (Corazza \& Malliaris, 2002; Grech \& Mazur, 2004; Dominique, 2012). Therefore, the financial researches adopted minutely the Hurst exponent to analyze their financial time series data. Based on these advantages, this study adopted the Hurst exponent to identify the dynamics behavior of inventory under each ordering heuristic and different factors.

\section{Supply Chain Factors}

\subsection{Demand Pattern}

Demand of commodities signifies the craving supported by the required purchasing power. Demand refers to the quantity of commodities that people are ready and in a situation to buy at a definite price. The demand pattern is a reflection that is generated from sales strategy of the commodity or market mechanism (such as sales promotions and price reductions). There are mainly two types of demand patterns (e.g., Step function and Broad-Pulse function) in the beer distribution simulation model. As sales promotions and price reductions have occurred in an extensive period of time, the demand may jump to a higher level also for an extended period of time; the demand function will appear like the step function. On the contrary, the broad pulse function is generated in the situation that is the demand stimuli increase are rather temporary and the demand increase for a short period of time. These demand patterns of the step function and broad pulse function are illustrated in Figure 3.

The step function in this study, we set that the original demand level is four units before fifth period from the simulation beginning and the shifted level is eight units after the fifth period to the simulation ending, as illustrated in Figure 4(a).

Additionally, the broad pulse function in this paper, we set that the original demand level is four units before fifth period from the simulation beginning, the first shifted level is eight units after the fifth period to the 500th period, the second shifted level is four units after the 500th period to the 1000th period, the third shifted level is eight units after the 1000th period to the 1500th period, the final shifted level is four units after the 1500th period to the simulation ending, as illustrated in Figure 4(b).

\subsection{Lead Time}

The lead time includes the orders transmission delays and the products shipment delays between two seriate levels. In this study considered the differentiation of lead time length that include short lead time and long lead 
time. The he products shipment delays are set as one time period in the short lead time and are set as two time period in the short lead time. The orders transmission delays are set as one time period in all kinds of lead time.

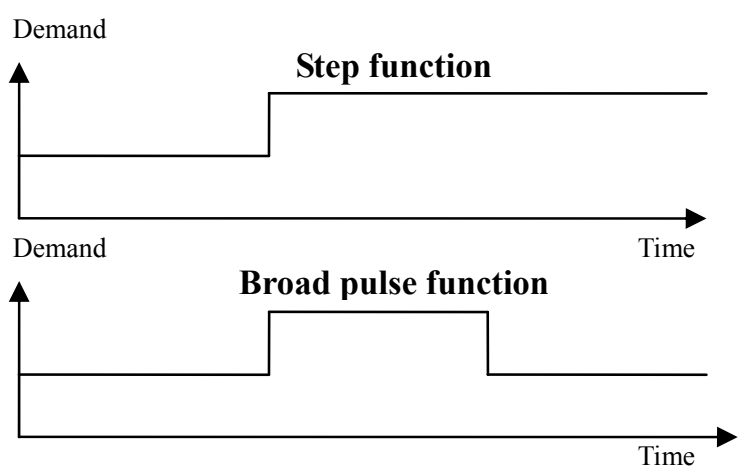

Figure 3. The diagram of demand patterns

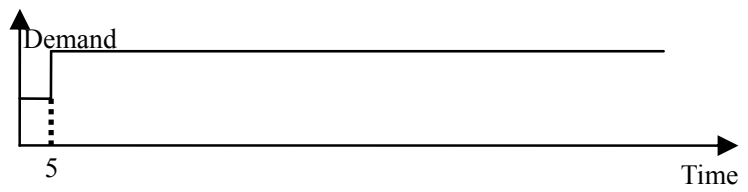

Figure 4(a). The diagram of the step function in this research setting

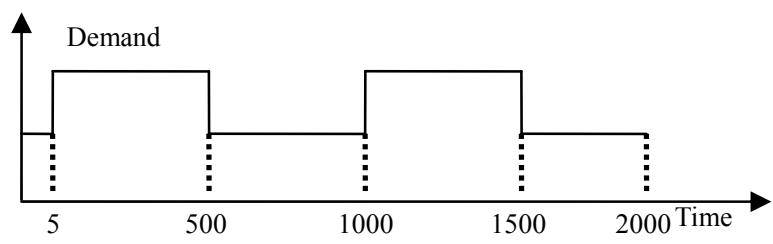

Figure 4(b). The diagram of the broad pulse function in this research setting

\subsection{Demand Information Sharing}

In the original beer distribution simulation model, no customers' demand information sharing is considered. As IT application in supply chain increase, information sharing with IT becomes more widespread and cost of information sharing is significantly down. This study considered the differentiation of setting into sharing demand information and no sharing. The sharing information, the customer's demand information must be shared from retail to other entities. Therefore, these entities' decision makers can reference the customers' demand information to make the order decision.

\subsection{RFID Utilization Effectualness}

Sahin and Dallery (2009) and Ustundag and Tanyas (2009) surveyed numerous academic literatures that are related to the topic of inventory management. These literatures indicated that deficient shipment, stealing, and misplacement are major causes of the inaccuracy inventory. Ustundag and Tanyas (2009) set these rates of three error types for with RFID and without RFID in Table 1.

The above mentioned setting of the research, it show that numerous RFID researches are only concerned "With RFID" and "Without RFID" and the "With RFID" is assumed that the perfect RFID. Unfortunately, in an actual RFID application, the perfect RFID is extremely difficult because the read rate of RFID is influenced by some interference sources (the read rate is not $100 \%$ ) and the fitness of RFID system for business process systems in enterprises is not completely appropriate. Therefore, the grade of RFID utilization effectualness can influence the supply chains efficiency and efficacy and this is affected by the read rate of RFID and the fitness of RFID system for business process systems. The worse read rate of RFID and the worse fitness of RFID system for business process systems can increase the length of lead time and influence the operation efficiency in supply chain. Therefore, this study considered various circumstances of the RFID utilization effectualness to survey the dynamics behavior of inventory under each situation. 
Table 1. The setting values of rates of error types for the RFID utilization

\begin{tabular}{cccc}
\hline RFID utilization & \multicolumn{3}{c}{ Error type } \\
\cline { 2 - 4 } & Deficient shipment(\%) & Stealing(\%) & Misplacement(\%) \\
\hline With RFID & 0 & 0 & 0 \\
Without RFID & 0.3 & 0.5 & 2 \\
\hline
\end{tabular}

These circumstances of the RFID utilization effectualness include that "The perfect RFID situation", "The better read rate and better fitness of RFID system situation", "The better read rate and worse fitness of RFID system situation", "The worse read rate and better fitness of RFID system situation", "The worse read rate and worse fitness of RFID system situation", and "The without RFID situation". These circumstances of the RFID utilization effectualness can result various rates of deficient shipment, stealing, and misplacement. The setting values of rates of error types for the RFID utilization effectualness is presented in Table 2.

Table 2. The rates of error types for each circumstances of the RFID utilization effectualness

\begin{tabular}{ccccc}
\hline $\begin{array}{c}\text { Circumstances of the RFID } \\
\text { utilization effectualness }\end{array}$ & Read rate(\%) & $\begin{array}{c}\text { Deficient } \\
\text { shipment(\%) }\end{array}$ & Stealing(\%) & Misplacement(\%) \\
\hline $\begin{array}{c}\text { The perfect RFID situation } \\
\text { The better read rate and better } \\
\text { fitness of RFID system situation }\end{array}$ & 100 & 0 & 0 & 0 \\
$\begin{array}{c}\text { The better read rate and worse } \\
\text { fitness of RFID system situation } \\
\begin{array}{c}\text { The worse read rate and better } \\
\text { fitness of RFID system situation }\end{array}\end{array}$ & 80 & 0.03 & 0.05 & 0.5 \\
$\begin{array}{c}\text { The worse read rate and worse } \\
\text { fitness of RFID system situation } \\
\text { Without RFID }\end{array}$ & 30 & 0.1 & 0.2 & 1 \\
\hline
\end{tabular}

\section{Research Design and Analysis}

The scenarios of this study are composed by two types of demand patterns (Step function and Broad Pulse function), two kinds of lead time length (Short lead time and Long lead time), two options of demand information sharing (Share and not share), 6 circumstances of RFID utilization effectualness and four multiple entities levels (Factory, Distributor, Wholesaler, and Retailer), hence, there are 192 scenarios in this simulation. The coding table of simulation scenario is shown in the Appendix A.

The simulation model of this study is based on the beer distribution model. Hence, these equations, settings, and initial parameters values of beer distribution model and parameters of RFID utilization effectualness are entered in our simulation model. The detailed description of these settings, initial parameters values and equations in our simulation model is shown in the Appendix B. Our simulation model is constructed by Vensim that is the well-known system dynamics simulation software. We observed and analyzed the inventory dynamic behavior by 65 parameter sets of ordering heuristic (an increment of 0.1 from 0 to 1 for $A$ and $B$, and $A \geq B$ ) for each scenario (The total of simulation cases are 12480) and 2000 time periods run time for each simulation case. In order to decrease the degree of complex in our analysis, we clustered ordering decisions (parameter sets) into several different groups with K-means. The clustering criteria are based on two rules: (1) Dynamics of ordering decisions (parameter sets) are similar in the same group; (2) These group size of each groups should be reasonably manageable. The size of ordering decisions for each group is expressed in Table 3. 
Table 3. The result of ordering decisions clustering

\begin{tabular}{cccccccccccc}
\hline Group & $\mathbf{1}$ & $\mathbf{2}$ & $\mathbf{3}$ & $\mathbf{4}$ & $\mathbf{5}$ & $\mathbf{6}$ & $\mathbf{7}$ & $\mathbf{8}$ & $\mathbf{9}$ & $\mathbf{1 0}$ & $\mathbf{1 1}$ \\
\hline Size & 3 & 5 & 2 & 4 & 3 & 4 & 7 & 13 & 5 & 6 & 13 \\
\hline
\end{tabular}

\section{Results of Simulation}

Through the observation of the average of Hurst exponents for the inventory dynamics, this study investigated the effects of RFID utilization effectualness on the inventory. In the without RFID circumstances, the average of Hurst exponents is shown in the Figure 5(a) and Figure 5 (b). Greater parts of the average of Hurst exponents are closely 0 in Group 1-6 and some of the average of Hurst exponents is greater than 0 in Group 7-11. The result of the Figure 5(a) implies that the inventory dynamic is extremely chaotic and unstable in Group 1-6, the ordering heuristic of which are $0.4 \leq A \leq 1.0$ and $0 \leq B \leq 0.5$. This finding is indicated that the enormous disparity between these determined parameters can cause the inventory to be more instable, hence in order to avoid the unstable supply chain, managers should select the determined parameters of upper Groups (Group 7-11). Next the following analysis, we mainly focused on lower groups (Group 1-6), that typically exhibit chaotic behaviors, to investigate the effects of supply chain factors.

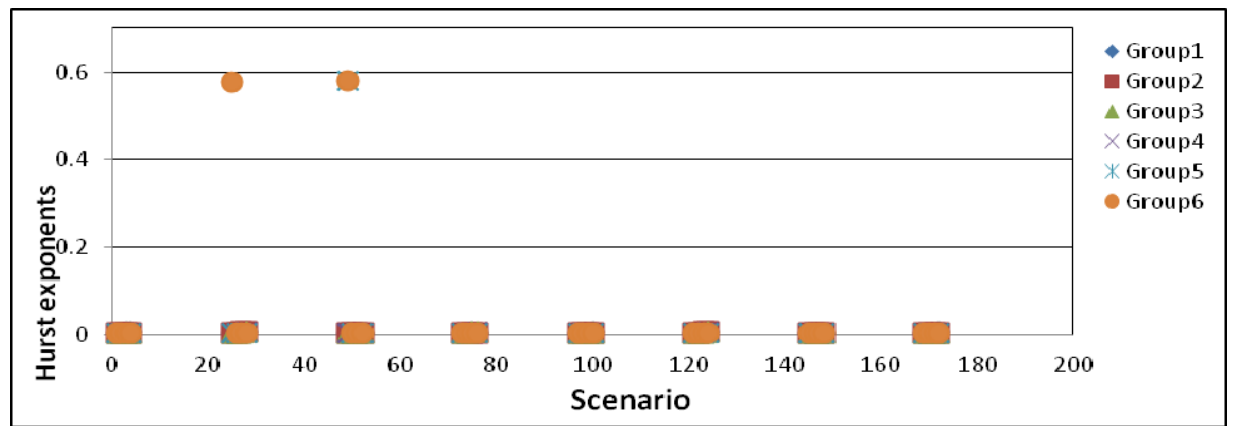

Figure 5(a). The average of the Hurst exponents under without RFID in Group 1- Group 6

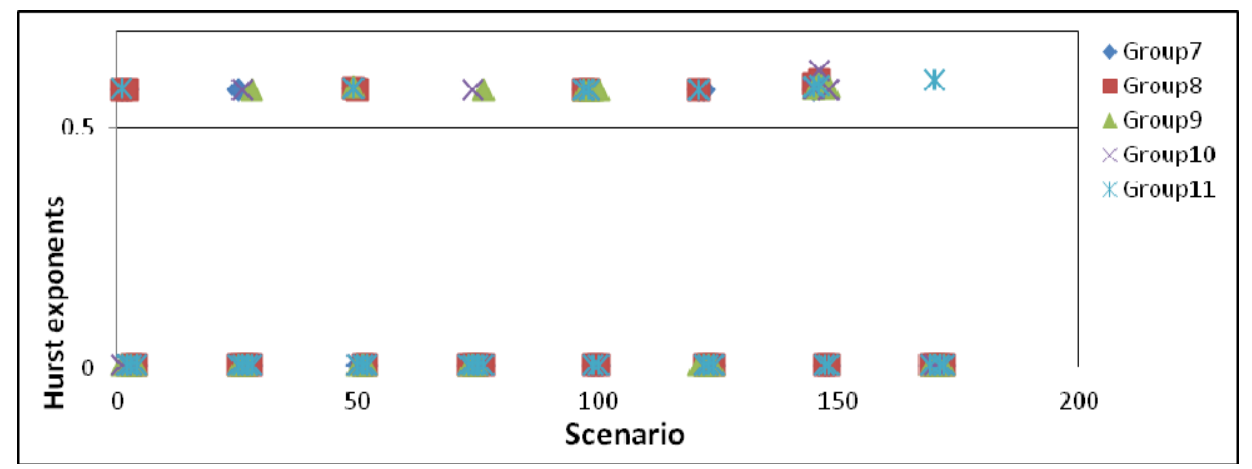

Figure 5(b). The average of the Hurst exponents under without RFID in Group 7- Group 11

Exposing the effects of the RFID utilization effectualness on the inventory, we demonstrated the average of the Hurst exponents in other circumstances of RFID utilization effectualness that include "The perfect RFID" (C2), "The better read rate and better RFID system integration" (C3), "The better read rate and worse RFID system integration" (C4), "The worse read rate and better RFID system integration" (C5), and "The worse read rate and worse RFID system integration" (C6), in Group 1-6 (Figure 6(a)- Figure 6(e)) and compared with the without RFID (C1).

The results show that the RFID utilization effectualness and inventory stability are significantly related. The grade of RFID utilization effectualness is better that the supply chain network of inventory is more stable (the greater part of the average of Hurst exponents is $>0.5$ ). Conversely, the grade of RFID utilization effectualness is worse than the amount of the average of Hurst exponents is substantially increased. 


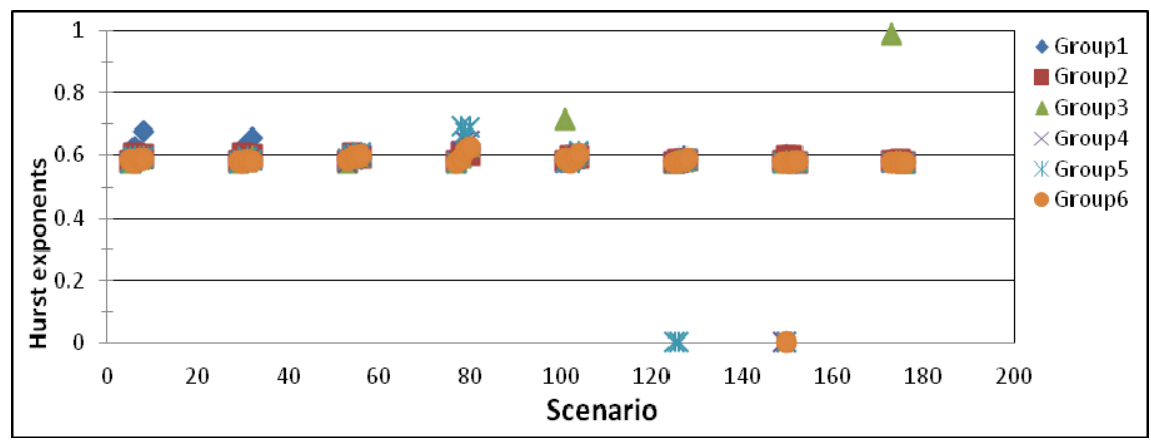

Figure 6(a). The average of the Hurst exponents for C2 in Group 1-6

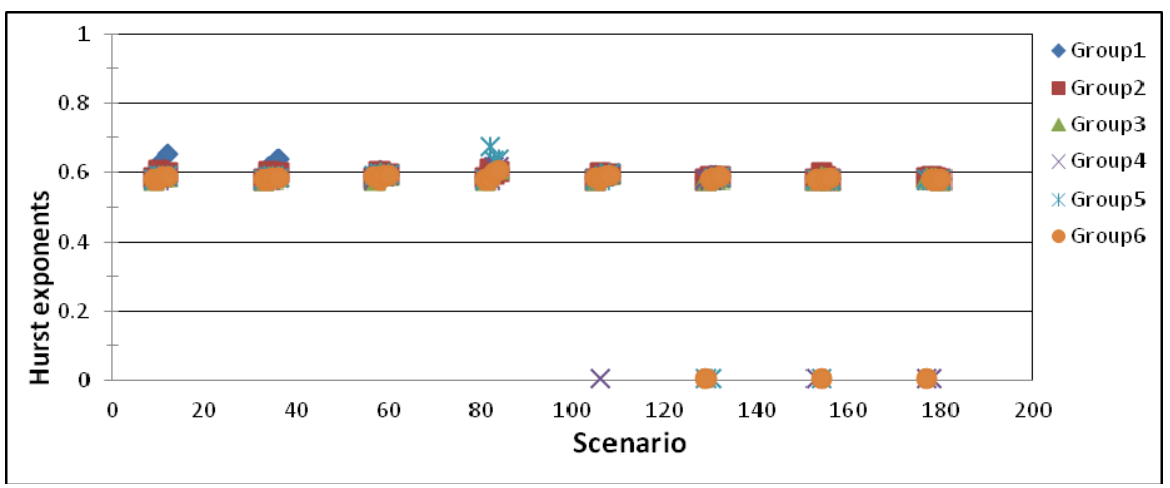

Figure 6(b). The average of the Hurst exponents for C3 in Group 1-6

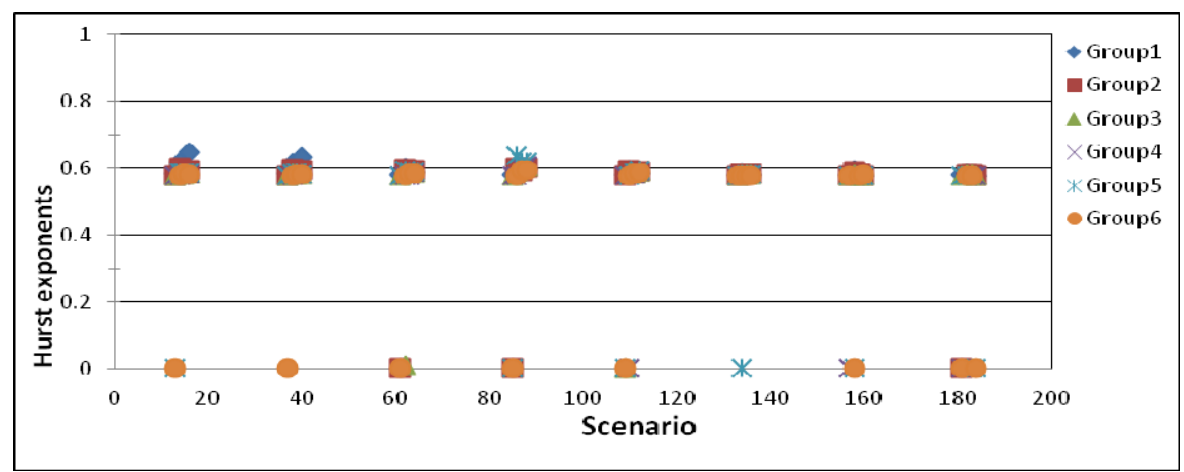

Figure 6(c). The average of the Hurst exponents for C4 in Group 1-6

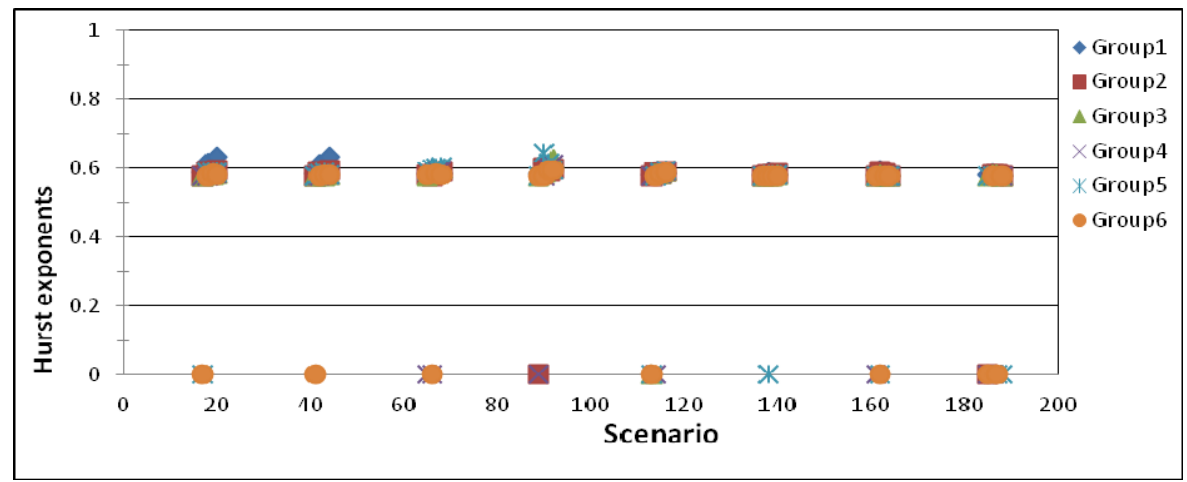

Figure 6(d). The average of the Hurst exponents for C5 in Group 1-6 


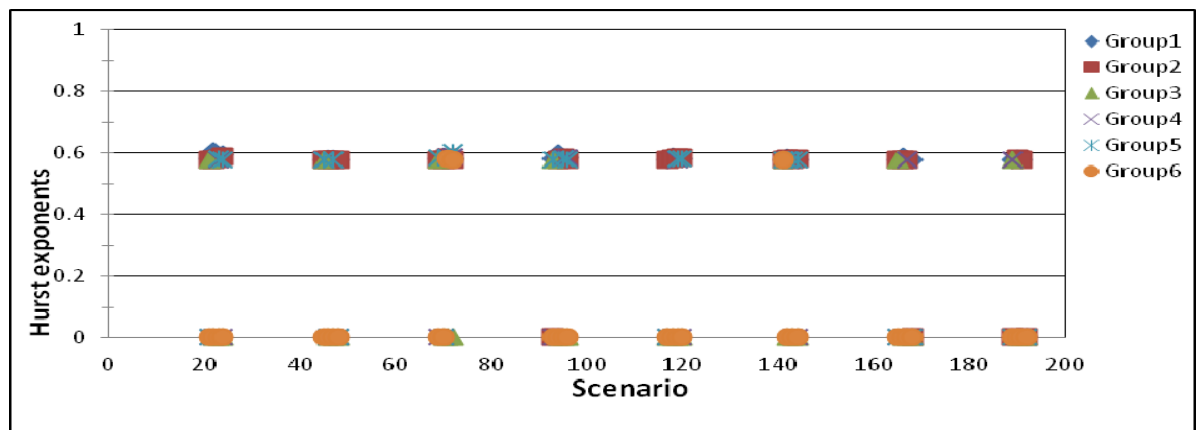

Figure 6(e). The average of the Hurst exponents for C6 in Group 1-6

Next the following analysis, we explored the main effect of each supply chain factors and the interaction affects of between RFID utilization effectualness and other supply chain factors on the effective inventories. The benefit of this analysis is the understanding effect of each supply chain factors for the practice of RFID investment in the supply chain management. This paper utilized the analysis of variance (ANOVA) to explore the main effect and interactions effect for each groups. The result is summarized in the Appendix $\mathrm{C}$ and discussions as follows.

\subsection{Supply Chain Level Effect}

The supply chain level effect is significant for all groups and the degree of chaos of the inventory generally increases as it goes upstream in the supply chain. The amplification of chaos in inventory is observed in other studies about the bullwhip effect.

\subsection{Demand Pattern Effect}

As the market demand pattern is the step demand function, the supply chain system becomes more uncertain and chaotic. It is more manifest in the Group 1 and Group 2, the demand pattern effect of which is significant with p-Value $<0.001$ and $A$ and $B$ ranges of which are from 0.65 to 1.0 and from 0.0 to 0.25 . Additionally, although Group 3-5 of the demand pattern is the step demand function and the supply chain system is more chaotic, these groups of demand patterns effect are not significant. Finally, Group 6-11 of the demand patterns is the broad pulse function and the demand pattern effect in these groups is significant. These above results are indicated that the sustained demand change for a longer period can lead supply chain system to become uncertain and chaotic.

\subsection{Lead Time Effect}

The benefit of lead time decrement is manifestly offset by the enormousness difference between $A$ and $B$ in Group 1, the lead time effect is conformably significant in other groups. This results is indicated that the lead time decreasing generally can diminish the negative impact of inventory discrepancies and supply line discrepancies and reduce time delay to reduce the supply chain system uncertainty.

\subsection{Demand Information Sharing Effect}

The demand information sharing effect is significant in Group 1,2, and 5. It is attractive to note that sharing demand information appears to lead the supply chain to be more chaotic in Group 1 and 2, but less chaotic in Group 5. Only when a proper decision region (e.g., Group 5) is adopted, it is advantageous to demand information sharing. This result is slightly divergent to the general opinion that benefit of demand information sharing for supply chain.

\subsection{RFID Utilization Effectualness Effect}

The RFID utilization effectualness effect is significant in all groups. The demonstration of Figure. 5 and Figure. 6 are shown that RFID utilization can diminish lead time, the inventory inaccuracy, and the supply chain system uncertainty. On the other hand, the interactions effect of RFID utilization effectualness with supply chain level and lead time are more significant. These above interactions effects are explained that the RFID benefit augments at upper supply chain levels and longer lead time.

Finally, we investigated deeply RFID utilization effectualness for each supply chain level in lower groups(Group 1-6), this result is shown in Table 4. In the retailer and inventory dynamics is stable, there are all of groups in the perfect RFID circumstance, and there are 5 groups in the better read rate and better fitness of RFID system circumstance. This result is implied that the inventory stability of retailer play the critical part in supply chain 
dynamics. Hence, retailer must establish the perfect RFID or better read rate and better fitness of RFID system to dominate effectively the customers of purchase and inventory. As retailers can dominate effectively the customers of purchase and inventory by RFID, they can estimate exactly the future demands and place appropriate order in orders flows. In other entities and inventory dynamics is stable, there are 5 groups in the perfect RFID circumstance, there are 4 to 5 groups in the better read rate and better fitness of RFID system circumstance, and there are 4 groups in the better read rate and worse fitness of RFID system circumstance. The result is implied that other entities investing at the least the better read rate RFID, the combination of which can diminish significantly the system uncertainty.

Table 4. The number of groups under each inventory dynamics, each circumstances of RFID utilization effectualness and each chain level in Group 1-6

\begin{tabular}{|c|c|c|c|c|c|c|c|c|}
\hline & \multirow{2}{*}{$\begin{array}{l}\text { Inventory } \\
\text { dynamics }\end{array}$} & \multirow[t]{2}{*}{ The number of groups } & \multicolumn{6}{|c|}{ Circumstances of RFID utilization effectualness } \\
\hline & & & C1 & $\mathbf{C 2}$ & C3 & $\mathbf{C 4}$ & $\mathbf{C 5}$ & C6 \\
\hline \multirow[t]{2}{*}{$\mathrm{R}$} & Stable & & 0 & 6 & 5 & 3 & 2 & 1 \\
\hline & Chaotic & & 6 & 0 & 1 & 3 & 4 & 5 \\
\hline \multirow[t]{2}{*}{ W } & Stable & & 0 & 5 & 5 & 4 & 3 & 2 \\
\hline & Chaotic & & 6 & 1 & 1 & 2 & 3 & 4 \\
\hline \multirow[t]{2}{*}{$\mathrm{D}$} & Stable & & 0 & 5 & 5 & 4 & 2 & 1 \\
\hline & Chaotic & & 6 & 1 & 1 & 2 & 4 & 5 \\
\hline \multirow[t]{2}{*}{$\mathrm{F}$} & Stable & & 0 & 5 & 4 & 4 & 2 & 1 \\
\hline & Chaotic & & 6 & 1 & 2 & 2 & 4 & 5 \\
\hline
\end{tabular}

Notation: C1: The without RFID, C2: The perfect RFID, C3: The better read rate and better fitness of RFID system, C4: The better read rate and worse fitness of RFID system, C5: The worse read rate and better fitness of RFID system, C6: The worse read rate and worse fitness of RFID system, R: Retailer, W: Wholesaler, D: Distributor, F: Factory

\section{Conclusion}

RFID applications in supply chain have been getting significant considerable attentions on the commercial applications and academia over the last few years. How to accurately measure the benefits and effects of RFID implementation is more momentous in e-SCM researches. This study explored the effect of various circumstances of the RFID utilization effectualness, lead time, demand pattern, and demand information sharing on the inventory dynamics with the Hurst exponent in the beer distribution simulation model. Hurst exponent is an eminent quantitative method to identify and characterize the chaotic phenomenon in a deterministic nonlinear system. Through the Hurst exponent analysis, the research finds that the more comparable determined parameters of the stock discrepancies and supply line discrepancies, the more stable market demand, shorter lead time, and better RFID utilization effectualness can diminish effectively instability in supply chain. In addition, this research explored various circumstances of RFID utilization effectualness under each supply chain entities to discover the minimum requirement of RFID implementation in each supply chain entities. Through this deeply investigation, the research suggest retailers must invest least the better read rate of RFID hardware and better fitness of RFID system on the retailers' business system and other entities must adopt least the better read rate RFID in their storehouse management process.

\section{References}

Basinger, K. L. (2006). Impact of inaccurate data on supply chain inventory performance. Ph.D. Thesis, The Ohio State University.

Cooper, M. C., Lambert, D. M., \& Pagh, J. D. (1997). Supply chain management: More than a new name for logistics. International Journal of Logistics Management, $8(1)$, 1-14. http://dx.doi.org/10.1108/09574099710805556

Corazza, M., \& Malliaris, A. G. (2002). Multi-Fractality in Foreign Currency Markets. Multinational Finance Journal, 6(2), 65-98.

Demiralp, G., Guven, G., \& Ergen, E. (2012). Analyzing the benefits of RFID technology for cost sharing in construction supply chains: A case study on prefabricated precast components. Automation in Construction, 
24, 120-129. http://dx.doi.org/10.1016/j.autcon.2012.02.005

Dominique, C. R. (2012). Could investors' expectations explain temporal variations in Hurst's exponent, Loci of Multifractal Spectra, and statistical prediction errors? The case of the S\&P 500 Index. International Business Research, 5(5), 8-15. http://dx.doi.org/10.5539/ibr.v5n5p8

Feder, J. (1988). Fractals. New York: Plenum Press.

Fleisch, E., \& Tellkamp, C. (2005). Inventory inaccuracy and supply chain performance: a simulation study of a retail supply chain. International Journal of Production Economics, 95(3), 373-385. http://dx.doi.org/10.1016/j.ijpe.2004.02.003

Gaukler, G. M., Seifert, R. W., \& Hausman, W. (2007). Item-level RFID in the retail supply chain. Production and Operations Management, 16(1), 65-76. http://dx.doi.org/10.1111/j.1937-5956.2007.tb00166.x

Grech, D., \& Mazur, Z. (2004). Can one make any crash prediction in finance using the local Hurst exponent idea? Physica A: Statistical Mechanics and its Applications, 336, 133-145. http://dx.doi.org/10.1016/j.physa.2004.01.018

Gunasekaran, A., \& Ngai, E. W. T. (2004). Information systems in supply chain integration and management. European Journal of Operational Research, 159(2), 269-295. http://dx.doi.org/10.1016/j.ejor.2003.08.016

Heese, H. S. (2007). Inventory record inaccuracy, double marginalization, and RFID adoption. Production and Operations Management, 16(5), 542-553. http://dx.doi.org/10.1111/j.1937-5956.2007.tb00279.x

Hurst, H. E. (1951). Long-term storage of reservoirs: an experimental study. Transactions of the American society of civil engineers, 116, 770-799.

Jarmain, W. E. (1963). Problems in Industrial Dynamics. Cambridge: MIT Press.

Lee, Y. M., Cheng, F., \& Leung, Y. T. (2004). Exploring the impact of RFID on supply chain dynamics. In Proceeding of the 2004 Winter Simulation Conference, Washington, D.C., December 5-8. http://dx.doi.org/10.1109/WSC.2004.1371441

Leung, Y. T., Cheng, F., Lee, Y. M., \& Hennessy, J. J. (2007). A Tool Set for Exploring the Value of RFID in a Supply Chain. Springer Series in Advanced Manufacturing. http://dx.doi.org/10.1007/978-1-84628-607-0_3

Li, S., Visich, J. K., Khumawala, B. M., \& Zhang, C. (2006). Radio frequency identification technology: applications, technical challenges and strategies. Sensor Review, 26(3), 193-202. http://dx.doi.org/10.1108/02602280610675474

Malik, Y., Niemeyer, A., \& Ruwadi, B. (2011). Building the supply chain of the future. Mckinsey Quarterly, 1, 62-71.

Prater, E., Frazier, G. V., \& Reyes, P. M. (2005). Future impacts of RFID on e-supply chains in grocery retailing. International Journal of Supply Chain Management, 10(2), 134-142. http://dx.doi.org/10.1108/13598540510589205

Raghunathan, M., \& Madey, R. M. (1999). A firm-level framework for planning electronic commerce information systems infrastructure. International Journal of Electronic Commerce, 4(1), 121.

Sahin, E., \& Dallery, Y. (2009). Assessing the impact of inventory inaccuracies within a newsvendor framework. European Journal of Operational Research, 197(3), 1108-1118. http://dx.doi.org/10.1016/j.ejor.2008.03.042

Simchi-Levi, D., Kaminsky, P., \& Simchi-Levi, E. (2000). Designing and Managing the Supply Chain: Concepts, Strategies, and Case Studies. Irwin/McGraw-Hill, Boston.

Sprott, J. C., \& Rowlands, G. (1995). Chaos Data Analyzer: The Professional Version. Physics Academic Software, New York.

Sterman, J. D. (1989). Modeling managerial behavior: Misperceptions of feedback in a dynamic decision making experiment. Management Science, 35, 321-339. http://dx.doi.org/10.1287/mnsc.35.3.321

Szmerekovsky, J. G., \& Zhang, J. (2008). Coordination and adoption of item-level RFID with vendor managed inventory. International Journal of Production Economics, 114(1), 388-398. http://dx.doi.org/10.1016/j.ijpe.2008.03.002

Szmerekovsky, J. G., Tilson, V., \& Zhang, J. (2011). Analytical model of adoption of item level RFID in a two-echelon supply chain with shelf-space and price-dependent demand. Decision Support Systems, 51(4), 833-841. http://dx.doi.org/10.1016/j.dss.2011.02.002 
Tracey, M., Lim, J. S., \& Vonderembse, M. A. (2005). The impact of supply chain management capabilities on organization performance. Supply Chain Management, 10(3), 179-191. http://dx.doi.org/10.1108/13598540510606232

Tumaini, M. K. (2011). Obstacles to Process Integration along the Supply Chain: Manufacturing Firms Perspective. International Journal of Business and Management, 6(5), 105-113.

Tzeng, S. F., Chen, W. H., \& Pai, F. Y. (2008). Evaluating the business value of RFID: evidence from five case studies. International Journal of Production Economics, 112, 601-613. http://dx.doi.org/10.1016/j.ijpe.2007.05.009

Ustundag, A., \& Tanyas, M. (2009). The impacts of radio frequency identification (RFID) technology on supply chain costs. Transportation Research Part E: Logistics and Transportation Review, 45(1), 29-38. http://dx.doi.org/10.1016/j.tre.2008.09.001

Wang, L. C., Lin, Y. C., \& Lin, P. H. (2007). Dynamic mobile RFID-based supply chain control and management system in construction. Advanced Engineering Informatics, 21, 377-390. http://dx.doi.org/10.1016/j.aei.2006.09.003

Williams, G. P. (1997). Chaos Theory Tamed. London: Taylor \& Francis.

Wolf, A., Swift, J. B. V., \& Swinney, H. L. (1985). Determining Lyapunov exponents from a time series. Physica D, 16, 285-317. http://dx.doi.org/10.1016/0167-2789(85)90011-9

Yee, S. T. (2005). Impact analysis of customized demand information sharing on supply chain performance. International Journal of Production Research, 43(16), 3353. http://dx.doi.org/10.1080/00207540500095779

Zhou, W. (2009). RFID and item-level information visibility. European Journal of Operational Research, 198(1), 252-258. http://dx.doi.org/10.1016/j.ejor.2008.09.017

\section{Appendix}

Appendix 1. The coding table of simulation scenario

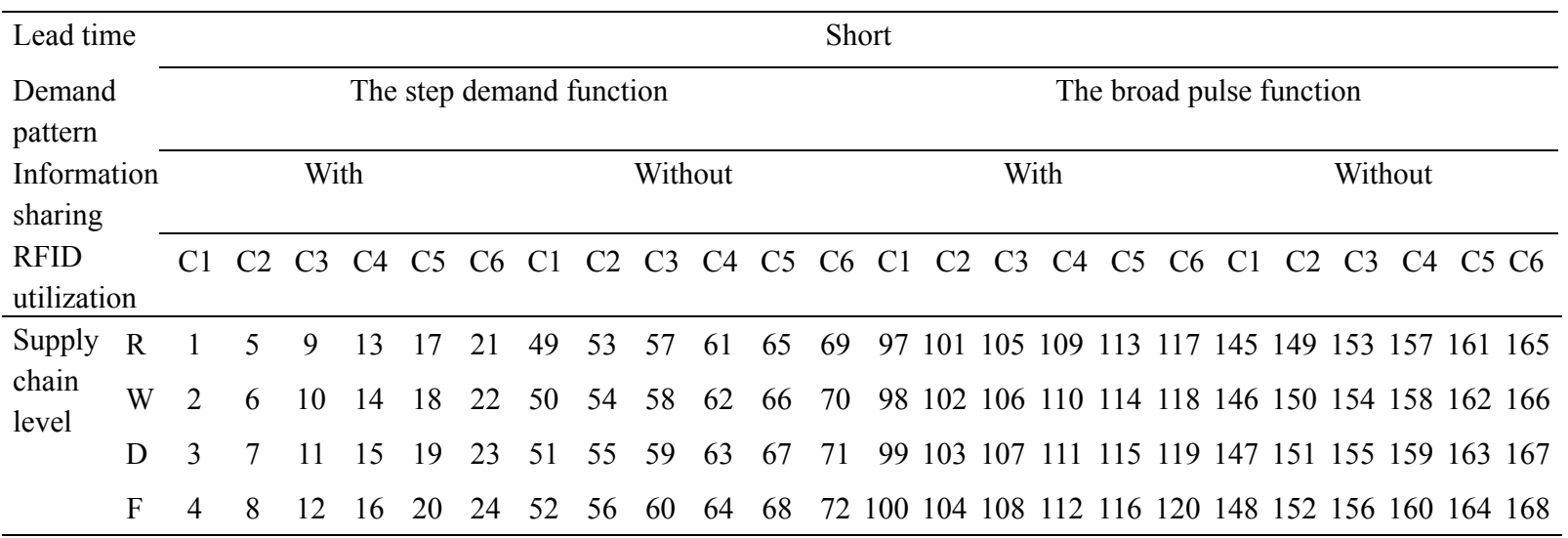

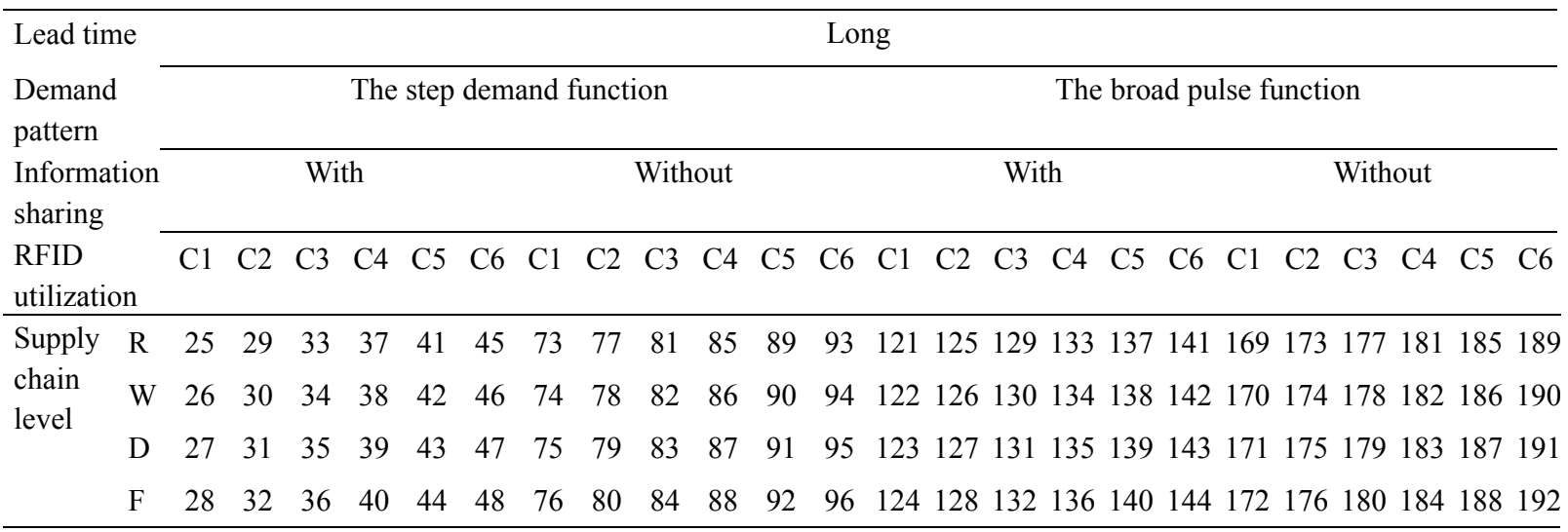

Notation: S1: The without RFID situation, S2: The perfect RFID situation, S3: The better read rate and better RFID system integration situation, S4: The better read rate and worse RFID system integration situation, S5: The 
worse read rate and better RFID system integration situation, S6: The worse read rate and worse RFID system integration situation, R: Retailer, W: Wholesaler, D: Distributor, F: Factory

Appendix 2. The ranges and initial values of parameters and simulation equations

\begin{tabular}{|c|c|}
\hline Variable(parameters) and defining equation & Comments \\
\hline ( & $0.0-1.0$, an increment of 0.1 \\
\hline$B, B \leq A$. & $0.0-1.0$, an increment of 0.1 \\
\hline Backlog $=$ INTEG $($ bFlow, 0$)$ & Backlog at retailer \\
\hline Backlog0 = INTEG $($ bFlow0, 0$)$ & Backlog at wholesaler \\
\hline Backlog $1=$ INTEG $($ bFlow 1,0$)$ & Backlog at distributor \\
\hline Backlog2 = INTEG(bFlow2, 0) & Backlog at factory \\
\hline bFlow $=$ ORDer - sold & Accumulation of backlog at retailer \\
\hline bFlow $0=$ ordered - sold 0 & Accumulation of backlog at wholesaler \\
\hline bFlow $1=$ ordered $0-$ sold 1 & Accumulation of backlog at distributor \\
\hline bFlow $2=$ ordered $1-$ sold 2 & Accumulation of backlog at factory \\
\hline coming $=$ ordered 2 & Materials in transit to factory \\
\hline Cost $=$ INTEG $($ cost increase, 0$)$ & Total supply chain cost \\
\hline $\begin{array}{l}\text { cost increase }=1 \times(\text { Backlog }+ \text { Backlog } 0+\text { Backlog } 1+\text { Backlog } 2) \\
+0.5 \times(\text { Inventory }+ \text { Inventory } 0+\text { Inventory } 1+\text { Inventory } 2)\end{array}$ & \\
\hline Eff Env $=$ Inventory - Backlog & Effective Inventory at retailer \\
\hline Eff Inv0 = Inventory0 - Backlog 0 & Effective Inventory at wholesaler \\
\hline Eff Inv1 = Inventory $1-$ Backlog 1 & Effective Inventory at distributor \\
\hline Eff Inv2 = Inventory $2-$ Backlog2 & Effective Inventory at factory \\
\hline In $=$ DELAY FIXED $($ sold $0,4 \times(1-$ RFID read rate $), 4)$ & $\begin{array}{l}\text { Incoming orders at retailer for the short lead } \\
\text { time; RFID read rate(see Table 2) }\end{array}$ \\
\hline In $=$ DELAY FIXED $($ sold $0,8 \times(1-$ RFID read rate $), 4)$ & $\begin{array}{l}\text { Incoming orders at retailer for the long lead } \\
\text { time; RFID read rate(see Table 2) }\end{array}$ \\
\hline In0 = DELAY FIXED(sold1, $4 \times(1-$ RFID read rate $), 4)$ & $\begin{array}{l}\text { Incoming orders at wholesaler for the short } \\
\text { lead time; RFID read rate(see Table 2) }\end{array}$ \\
\hline In0 = DELAY FIXED(sold1, $8 \times(1-$ RFID read rate $), 4)$ & $\begin{array}{l}\text { Incoming orders at wholesaler for the long } \\
\text { lead time; RFID read rate(see Table 2) }\end{array}$ \\
\hline In $1=$ DELAY FIXED(sold2, $4 \times(1-$ RFID read rate $), 4)$ & $\begin{array}{l}\text { Incoming orders at distributor for the short } \\
\text { lead time; RFID read rate(see Table 2) }\end{array}$ \\
\hline In $1=$ DELAY FIXED $($ sold2, $8 \times(1-$ RFID read rate $), 4)$ & $\begin{array}{l}\text { Incoming orders at distributor for the long } \\
\text { lead time; RFID read rate(see Table 2) }\end{array}$ \\
\hline In $2=$ DELAY FIXED $($ coming, $4 \times(1-$ RFID read rate $), 4)$ & $\begin{array}{l}\text { Incoming orders at factory for the short lead } \\
\text { time; RFID read rate(see Table 2) }\end{array}$ \\
\hline In2= DELAY FIXED (coming, $8 \times(1-$ RFID read rate $), 4)$ & $\begin{array}{l}\text { Incoming orders at factory for the long lead } \\
\text { time; RFID read rate(see Table 2) }\end{array}$ \\
\hline Inventory $=$ INTEG $(\mathrm{In}-$ sold, 12$)$ & Actual inventory at retailer \\
\hline Inventory $0=\operatorname{INTEG}(\operatorname{In} 0-\operatorname{sold} 0,12)$ & Actual inventory at wholesaler \\
\hline Inventory $1=$ INTEG(In1 - sold 1,12$)$ & Actual inventory at distributor \\
\hline Inventory $2=\operatorname{INTEG}(\operatorname{In} 2-\operatorname{sold} 2,12)$ & Actual inventory at factory \\
\hline ORDer $=4+\operatorname{STEP}(4,5)$ & The demand pattern for step demand function \\
\hline ORDer $=4+(4 \times$ PULSE TRAIN $(5,500,1000,1500))$ & The demand pattern for broad pulse function \\
\hline ordered $=$ DELAY FIXED(placed, 1,4$)$ & In transit orders by retailer \\
\hline ordered $0=$ DELAY FIXED(placed $0,1,4)$ & In transit orders by wholesaler \\
\hline
\end{tabular}


ordered $1=$ DELAY FIXED $($ placed $1,1,4)$

ordered $2=$ DELAY FIXED $($ placed $2,1,4)$

placed $=\operatorname{MAX}(0, \operatorname{SMOOTH}($ ORDer, smoothtime $)+A \times$

(S -(Inventory - Backlog) $-B \times(\mathrm{SL}-$ supplyL $))$ )

SMOOTHTIME $=1, \mathrm{~S}=12, \mathrm{SL}=2 \times$ supplyL

placed $0=\operatorname{MAX}(0$, SMOOTH(ordered, smoothtime $)+A \times$

$(\mathrm{S}-($ Inventory0 $-\mathrm{Back} \log 0)-B \times(\mathrm{SL} 0-$ supplyL 0$)))$

SMOOTHTIME $=1, \mathrm{~S}=12, \mathrm{SL} 0=2 \times \operatorname{supplyL0}$

placed $1=\operatorname{MAX}(0$, SMOOTH $($ ordered0, smoothtime $)+A \times$

$(\mathrm{S}-($ Inventory $1-$ Backlog1) $-B \times($ SL1 - supplyL1))

$\mathrm{SMOOTHTIME}=1, \mathrm{~S}=12, \mathrm{SL} 1=2 \times$ supplyL1

placed $2=\operatorname{MAX}(0$, SMOOTH $($ ordered 1, smoothtime $)+A \times$ $(\mathrm{S}-($ Inventory2-Backlog2 $)-B \times($ SL2 - supplyL2)) $)$

SMOOTHTIME $=1, \mathrm{~S}=12, \mathrm{SL} 2=2 \times$ supplyL2

placed $=\operatorname{MAX}(0$, FORECAST(ORDer, 1, 2) $+A \times$

$(\mathrm{S}-$ (Inventory-Backlog) $-B \times(\mathrm{SL}-$ supplyL $)))$

$\mathrm{S}=12, \mathrm{SL}=2 \times$ supplyL

placed0 $=\operatorname{MAX}(0$, FORECAST(ORDer, 2, 4) $+A \times$

(S -(Inventory0-Backlog0) $-B \times($ SL0 - supplyL0))

$\mathrm{S}=12, \mathrm{SL0}=2 \times$ supplyL0

placed $1=\operatorname{MAX}(0$, FORECAST(ORDer, 3, 6) $+A \times$ $(\mathrm{S}-($ Inventory1-Backlog1) $-B \times(\mathrm{SL1}-$ supplyL1))

$\mathrm{S}=12, \mathrm{SL} 1=2 \times$ supplyL1

placed2 $=\operatorname{MAX}(0$, FORECAST(ORDer, 4,8$)+A \times$

(S - (Inventory2-Backlog2) - $B \times($ SL2 - supplyL2))

$\mathrm{S}=12, \mathrm{SL} 2=2 \times$ supplyL2

sFlow $=$ placed - In

sFlow $0=$ placed $0-\operatorname{In} 0$

sFlow $1=$ placed $1-\operatorname{In} 1$

sFlow2 $=$ placed $2-\operatorname{In} 2$

sold $=$ MIN(Inventory + In, ORDer + Backlog $) \times$

$((100-$ - (misplacement + stealing + deficient shipment $)) / 100)$

sold $0=\operatorname{MIN}($ Inventory $0+\operatorname{In} 0$, ordered + Backlog 0$) \times$

$((100-($ misplacement $0+$ stealing $0+$ deficient shipment 0$)) / 100)$

sold $1=$ MIN $($ Inventory $1+\operatorname{In} 1$, ordered $0+$ Backlog 1$) \times$

$((100-$ (misplacement $1+$ stealing $1+$ deficient shipment 1$)) / 100)$

sold $2=\operatorname{MIN}($ Inventory $2+\operatorname{In} 2$, ordered $1+$ Backlog 2$) \times$

$((100-($ misplacement $2+$ stealing $2+$ deficient shipment 2$)) / 100)$

SupplyL $=$ INTEG(sFlow, 0$)$

SupplyL0 = INTEG(sFlow0, 0)

SupplyL1 $=$ INTEG $($ sFlow 1,0$)$

SupplyL2 = INTEG(sFlow2, 0$)$

INITIAL TIME $=0$

FINAL TIME $=2000$

SAVEPER $=$ TIME STEP

TIME STEP $=1$
In transit orders by distributor

In transit orders by factory

Orders placed by retailer without demand information sharing

Orders placed by wholesaler without demand information sharing

Orders placed by distributor without demand information sharing

Orders placed by factory without demand information sharing

Orders placed by retailer with demand information sharing

Orders placed by wholesaler with demand information sharing

Orders placed by distributor with demand information sharing

Orders placed by factory with demand information sharing

Supply line accumulation for retailer

Supply line accumulation for wholesaler

Supply line accumulation for distributor

Supply line accumulation for factory

Crates sold by retailer; misplacement, stealing, deficient shipment(see Table 2)

Crates sold by wholesaler; misplacement, stealing, deficient shipment(see Table 2)

Crates sold by distributor; misplacement, stealing, deficient shipment(see Table 2)

Crates sold by factory; misplacement, stealing, deficient shipment(see Table 2)

Supply line for retailer

Supply line for wholesaler

Supply line for distributor

Supply line for factory

The initial time for the simulation

The final time for the simulation

Frequency at which output is stored

The time step for the simulation 
Appendix 3. Main effects and two-factor interaction effects of supply chain factors in 11 regions

\begin{tabular}{|c|c|c|c|c|c|c|c|c|c|c|c|}
\hline \multirow[t]{2}{*}{ Factors } & \multicolumn{11}{|c|}{ p-Value } \\
\hline & Group1 & Group2 & Group3 & Group4 & Group5 & Group6 & Group7 & Group8 & Group9 & Group10 & Group11 \\
\hline \multirow[t]{2}{*}{ Demand pattern } & 0.0000 & 0.0002 & 0.5413 & 0.5764 & 0.1094 & 0.0054 & 0.0031 & 0.0454 & 0.0016 & 0.0001 & 0.0134 \\
\hline & $* * *$ & $* * *$ & & & & $* *$ & $* *$ & $*$ & $* * *$ & $* * *$ & * \\
\hline \multirow{2}{*}{$\begin{array}{l}\text { Information } \\
\text { sharing }\end{array}$} & 0.0000 & 0.0000 & 0.4354 & 0.0509 & 0.0001 & 0.7324 & 0.3422 & 0.1843 & 0.3803 & 0.3988 & 0.7167 \\
\hline & $* * *$ & $* * *$ & & & $* * *$ & & & & & & \\
\hline \multirow[t]{2}{*}{ Lead time } & 0.3247 & 0.0000 & 0.0000 & 0.0002 & 0.0000 & 0.0001 & 0.0000 & 0.0001 & 0.0037 & 0.0018 & 0.0032 \\
\hline & & $* * *$ & $* * *$ & $* * *$ & $* * *$ & $* * *$ & $* * *$ & $* * *$ & $* *$ & $* *$ & $* *$ \\
\hline \multirow{2}{*}{$\begin{array}{l}\text { Supply chain } \\
\text { level }\end{array}$} & 0.0000 & 0.0002 & 0.0001 & 0.0000 & 0.0000 & 0.0000 & 0.0000 & 0.0009 & 0.0001 & 0.0000 & 0.0000 \\
\hline & $* * *$ & $* * *$ & $* * *$ & $* * *$ & $* * *$ & $* * *$ & $* * *$ & $* * *$ & $* * *$ & $* * *$ & $* * *$ \\
\hline \multirow{2}{*}{$\begin{array}{l}\text { RFID utilization } \\
\text { effectualness }\end{array}$} & 0.0001 & 0.0001 & 0.0009 & 0.0006 & 0.0000 & 0.0431 & 0.0013 & 0.0000 & 0.0039 & 0.0018 & 0.0048 \\
\hline & $* * *$ & $* * *$ & $* * *$ & $* * *$ & $* * *$ & $*$ & $* *$ & $* * *$ & $* *$ & $* *$ & $* *$ \\
\hline \multirow{2}{*}{$\begin{array}{l}\text { Demand pattern } \\
\times \text { RFID } \\
\text { utilization } \\
\text { effectualness }\end{array}$} & 0.0007 & 0.0006 & 0.6074 & 0.6099 & 0.1096 & 0.0506 & 0.0488 & 0.0488 & 0.0498 & 0.0611 & 0.0706 \\
\hline & $* * *$ & $* * *$ & & & & & $*$ & $*$ & & & \\
\hline \multirow{2}{*}{$\begin{array}{l}\text { Information } \\
\text { sharing } \times \text { RFID } \\
\text { utilization } \\
\text { effectualness }\end{array}$} & 0.0031 & 0.0027 & 0.4428 & 0.0573 & 0.0002 & 0.7327 & 0.3714 & 0.1843 & 0.3842 & 0.3981 & 0.7209 \\
\hline & $* *$ & $* *$ & & & $* * *$ & & & & & & \\
\hline \multirow{2}{*}{$\begin{array}{l}\text { Lead time } \times \\
\text { RFID utilization } \\
\text { effectualness }\end{array}$} & 0.1988 & 0.0002 & 0.0002 & 0.0002 & 0.0006 & 0.0012 & 0.0008 & 0.0001 & 0.0026 & 0.0033 & 0.0025 \\
\hline & & $* * *$ & $* * *$ & $* * *$ & $* * *$ & $* *$ & $* * *$ & $* * *$ & $* *$ & $* *$ & $* *$ \\
\hline \multirow{2}{*}{$\begin{array}{l}\text { Supply chain } \\
\text { level } \times \text { RFID } \\
\text { utilization } \\
\text { effectualness }\end{array}$} & 0.0004 & 0.0005 & 0.0014 & 0.0013 & 0.0001 & 0.0498 & 0.0203 & 0.0337 & 0.0238 & 0.0245 & 0.0140 \\
\hline & $* * *$ & $* * *$ & $* *$ & $* *$ & $* * *$ & $*$ & $*$ & * & * & $*$ & $*$ \\
\hline
\end{tabular}

